\title{
Underreporting of earnings and the minimum wage spike
}

\author{
Mirco Tonin $1,2,3$
}

\author{
Correspondence: \\ m.tonin@soton.ac.uk \\ ${ }^{1}$ Economics Division, University of \\ Southampton, Southampton, UK \\ ${ }^{2}$ Economics Department, UniCredit \\ \& Universities Fellow, Central \\ European University, Budapest, \\ Hungary \\ ${ }^{3}$ IZA, Bonn, Germany
}

\begin{abstract}
This paper contributes to the policy debate on minimum wage by highlighting its role in enforcing compliance with fiscal rules in economies where underreporting of earnings is widespread. First, I propose a simple model exploring the interaction between the minimum wage and underreporting of earnings. Then, I provide supportive evidence by documenting a positive correlation within European labour markets between the proportion of full-time employees with earnings on the minimum wage and the extent of underreporting of earnings in the economy. The analysis presented in this paper suggests that a high spike in the wage distribution at the minimum wage level is, in some contexts, a fiscal issue, more than a labour market issue, and therefore it would be incorrect to consider a high spike as an indication of a binding minimum wage. Also, differentiating the minimum wage along dimensions related to earnings (e.g. education, sector, or occupation) makes sense from an enforcement perspective.
\end{abstract}

JEL codes: J38, H26

Keywords: Minimum wage, Spike, Underreporting, Tax evasion

\section{Introduction}

At what level to fix the minimum wage is a recurrent, and very often contentious, labour market policy issue in many countries. More fundamentally, in some countries like Germany there is currently a lively debate on whether or not to have a general statutory minimum wage. The degree of controversy surrounding decisions on minimum wage policy is not surprising, as they hinge on a complex balance between competing arguments. The minimum wage has implications both in terms of efficiency and equity, for the labour market and beyond, as a minimum wage may significantly affect prices and profits and thus consumption and investment patterns ${ }^{1}$. In this paper I contribute to the debate on minimum wage policy by highlighting one aspect that has been largely overlooked, namely its role in enforcing compliance with fiscal rules in economies where underreporting of earnings is widespread.

I start with a very simple observation: consider that in 2006 the minimum wage was $30 \%$ of the average wage in Romania and 38\% in the UK. In the same year, more than $8 \%$ of Romanian full-time employees earned the minimum wage, while the figure for the UK was a much lower $1.8 \%{ }^{2}$ Why such a big difference? Does this imply that the shape of the productivity distribution in the two countries is very different? Or that other institutions,

(c) 2013 Tonin; licensee Springer. This is an Open Access article distributed under the terms of the Creative Commons Attribution License (http://creativecommons.org/licenses/by/2.0), which permits unrestricted use, distribution, and reproduction in any medium, provided the original work is properly cited. 
like unemployment benefits, compress the wage distribution much more in the UK than in Romania? What I claim in this paper is that the difference in the size of the spike at the minimum wage level between Romania and the UK is actually related to the different incidence of so called "envelope wages", i.e. cash payments unreported to tax or social security authorities. Indeed, in the same period, $23 \%$ of Romanian employees admitted having been paid "cash-in-hand" by their employer, while the figure for the UK was just $1 \%$. To corroborate this claim, I will first introduce a labour market model with underreporting of earnings, where a spike at the minimum wage level emerges as a result of the optimal reporting behaviour by firms and workers. In particular, what I show in the model is that for a given level of the minimum wage, a looser enforcement of fiscal regulation is associated with a bigger spike and, quite naturally, with higher underreporting of earnings. Thus, a positive correlation between the spike at the minimum wage level and the extent of underreporting in the economy emerges through their common dependence on enforcement. I will then present a novel empirical observation: controlling for the minimum wage level, there is indeed a positive correlation within European labour markets between the proportion of full-time employees with earnings on the minimum wage and various measures of informality, like the percentage of employees receiving envelope wages. This has important policy implications that will be discussed in the conclusions.

The relevance of this aspect of minimum wage policy is due to the fact that underreporting of earnings is a serious issue in many countries ${ }^{3}$. In 2007 the European Commission conducted a survey on undeclared work using a representative sample of individuals in the European Union (European Commission 2007). In that survey, 5\% of all dependent employees admitted having received all or part of their salary as envelope or cash-inhand wages within the past 12 months. There is a considerable heterogeneity within the EU, with underreporting of earnings being particularly relevant in Central and Eastern Europe. Romania is the country with the highest incidence of envelope wages, with $23 \%$ of employees having received them in the last year. Latvia, Bulgaria, Poland, and Lithuania follow, all with a double digit share, while Estonia and Hungary position themselves just below, with cash-in-hand paid to $8 \%$ of employees. On the other hand, the phenomenon is virtually non existent in Germany, France, Luxembourg, Malta and the United Kingdom, with a marginal share of $1 \%$ of dependent employees receiving envelope wages. The phenomenon is of course present also outside the EU. For instance, in Ukraine a survey involving 600 households found that $30 \%$ of formal employees interviewed received part of their wage cash-in-hand (Williams 2007), while in Russia, 8\% of employees reported that they received part of their income "under the table" (Petrova 2005). Also regarding Russia, Gorodnichenko et al. (2009) study the impact of the flat tax reform of 2001 on tax evasion and find a large response by households. They motivate their methodology based on the consumption-income gap by the fact that for Russia "tax evasion was widespread, with employees quite likely practising as much tax evasion as the self-employed." In Turkey, firms belonging to the formal sector are estimated to underreport $28 \%$ of their wage bill (World Bank 2006), and in Argentina, "roughly 15 percent of workers receive pay partly on the books and partly off the books" (World Bank 2007). In its Eastern Europe and Central Asia Enterprise Survey in 2005, the World Bank asked firms to estimate what percentage of the actual wage bill the typical firm in their area of business reports for tax purposes. Private firms estimated underreporting to be above 15\% in Albania, Azerbaijan, Georgia, Kyrgyzstan, Macedonia, Russia, and Turkey. More directly linked to 
the minimum wage, a World Bank study on labour markets in Eastern Europe and the Former Soviet Union (World Bank 2005) notices how in several countries in the region "disproportionately high shares of workers cluster on declared wages at or just above the minimum wage (with evidence of additional undeclared incomes above the minimum)" and a report to the European Commission (European Commission 2004) underlines how "[c]haracterising the forms of informal economy in the CEE countries, special attention should be paid to the wide-spread practice of "envelope wages", where only the minimum wage is officially declared and an additional part is paid as cash in an envelope."

Despite this evidence, the literature on minimum wage and informality has focused mostly on Latin America ${ }^{4}$. The main issue in Latin America is the existence of a large informal sector where employees generally lack basic social or legal protections or employment benefits and the minimum wage legislation is not implemented. The literature usually looks at the impact of the minimum wage on the informal sector. For instance, Maloney and Nunez (2004) find that the minimum wage has an influence in the informal sector wage distribution in virtually all the countries they examine and, in some countries (Brazil, Mexico, Argentina, and Uruguay), the influence of the minimum wage seems far stronger on the informal sector than the formal. More recently, Lemos (2009) uses Brazilian data and finds a wage compression effect for both the formal and informal sectors, but no evidence of employment effects in either sector. However, Bosch and Manacorda (2010) find no significant effect of the minimum wage on informal workers' earnings in Mexico. To identify evasion costs associated with non-wage compensation and minimum wages, McIntyre (2009) develops and estimates on Brazilian data a model where workers can choose between legal or illegal employment, where legality is defined as abiding by the minimum wage and participating in a set of payroll taxes and mandated non-wage benefits. He shows how enforcement of a minimum wage law creates a clump of illegal workers at the minimum wage. The view of informality that I use here, and that better fits the European experience, is instead one where there is also an "intensive margin" to the compliance decision, where firms and workers operating in the formal economy may decide to partially underreport earnings to avoid paying taxes and social security contributions.

From a modelling perspective, it is worth noticing how, in a standard competitive labour market, there should be no spike at the minimum wage level, as "workers whose services are worth less than the minimum wage are discharged" (Stigler 1946), and the wage distribution should be truncated. In other models, a spike could appear because, for instance, of adjustments in working conditions (De Fraja 1999) or training (Acemoglu and Pischke 2003), or because of frictions in the labour market (Manning 2003; Flinn 2006). This paper provides support for a different mechanism explaining the presence of a spike even in a competitive labour market, based on the role of the minimum wage in the enforcement of fiscal regulation.

The rest of the paper is organized as follows. Next section briefly presents the model, while Section 3 shows the relationship between the spike and underreporting within European labour markets. The last section concludes by discussing policy implications.

\section{The model}

Here, I briefly sketch the model of a perfectly competitive labour market with underreporting of earnings developed in Tonin (2011) and study the relationship between the spike and underreporting. 
The purpose of the model is to illustrate in a simple and tractable way the mechanism behind the correlation between the size of the spike at the minimum wage level and the prevalence of underreporting of earnings in the economy. As such, I will greatly simplify the fiscal environment, assuming for instance proportional taxation and random audits by the tax authority, and the labour market, assuming no frictions and no choice about hours of work. However, the intuition behind the proposed mechanism is likely to hold more generally. Namely, the idea is that firms and workers base their decision on how much to report on the likelihood of being detected and fined in case of evasion. The minimum wage represents an additional constraint for firms' and workers' reporting decision, because if they wish to remain in the formal economy they need to declare at least the minimum. More firms and workers will find the minimum wage constraint to be actually binding if fiscal enforcement is weaker, thus generating a larger spike. Quite naturally, with weaker fiscal enforcement, underreporting is more prevalent in the economy, thus inducing the positive correlation.

Assume that a worker is characterized by a productivity $y_{i}$, distributed in the population according to $\operatorname{pdf} g(y)$ and $\operatorname{cdf} G(y)$ on the support $[y, \bar{y}]$, where $\underline{y} \geq 0$. Workers are employed by risk-neutral firms who have an obligation to withhold taxes and social security contributions at the proportional rate $t \in(0,1)$. The labour market is perfectly competitive. In the economy, it is possible to underreport earnings, so that a firm can deduct taxes from any tax base $x_{i} \in\left[0, y_{i}\right]$. With probability $\gamma \in[0,1]$, the tax authority inspects firms. The detection technology is imperfect, so that during an audit the tax authority may find evidence to impute an income $\hat{y}_{i} \in\left[0, y_{i}\right]$, where $\hat{y}_{i}$ has an uniform distribution over the support $\left[0, y_{i}\right]$. In case tax evasion is detected, i.e. when $\hat{y}_{i}>x_{i}$, the tax authority imposes the payment of due taxes plus an additional fine proportional to the assessed tax evasion $\theta t\left(\hat{y}_{i}-x_{i}\right)$, with $\theta>1$. Firms maximize expected profits, while workers maximize net income. It is possible to show (see Tonin 2011, for details) that the optimal reporting behaviour without a minimum wage is given by

$$
x_{i}^{*}=(1-\alpha) y_{i} \text { where } \alpha \equiv 1 /(\gamma \theta) .^{5}
$$

Introducing a minimum monthly wage $\varpi$ leaves high productivity workers (i.e. with $\left.y_{i}>\varpi /(1-\alpha)\right)$ unaffected and pushes low productivity workers (i.e. with $y_{i}<$ $\varpi \max \{1 /(2-2 \alpha), 1\}$ ) into the black market (if $\alpha>t / 2$ ) or into inactivity (if $\alpha \leq t / 2$ ). The remaining workers, those with intermediate productivity, increase their compliance to the minimum wage level, thus creating a spike whose size is given by

$$
S=\int_{\varpi \max \{1 /(2-2 \alpha), 1\}}^{\varpi /(1-a)} g(y) d y .
$$

What happens to the size of the spike when enforcement changes? It is possible to show that (see the Appendix for proof):

Proposition 1. When enforcement is not too weak, a decrease in enforcement increases the size of the spike at the minimum wage, both in absolute terms or relative to the officially employed workforce. When enforcement is weak, a sufficient condition for this to happen is a single peaked productivity distribution combined with a minimum wage binding for workers with productivity lower than the mode. 
What happens to the size of the informal economy when enforcement changes? It is possible to show that (see the Appendix for proof):

Proposition 2. When enforcement decreases, the size of the informal economy increases, both in absolute terms, relative to the formal economy, or relative to the economy as a whole.

Thus, for a given productivity distribution and minimum wage, as enforcement gets weaker, both the size of the informal economy and the size of the spike at the minimum wage level increase, giving rise to the positive correlation between these two quantities that will be documented in the next section.

\section{The relationship between the spike and underreporting}

In 2007 the European Commission conducted a survey about undeclared work (European Commission 2007). The survey interviewed almost 27,000 individuals from the $27 \mathrm{mem}$ ber states and asked specific questions about cash-in-hand payments by employers. For instance, the following question was asked to dependent employees:

"Sometimes employers prefer to pay all or part of the regular salary or the remuneration for extra work or overtime hours cash-in-hand and without declaring it to tax or social security authorities. Did your employer pay you all or part of your income in the last 12 months in this way?"

In case of a positive answer, the survey asked whether the cash-in-hand payment was part of the remuneration for regular work or for overtime hours or both ${ }^{6}$, and which percentage share of gross yearly income in the main job was received cash-in-hand ${ }^{7}$. In what follows, I use these questions to build different measures of underreporting of earnings by employees in EU countries.

This survey is unique in measuring undeclared work, and in particular envelope wages, on an EU wide basis and in a cross-nationally comparable way, even if the limitations of measuring sensitive issues like undeclared work through a direct survey should be acknowledged. Getting cross-country data on the size of the spike at the minimum wage level is also challenging. Until the end of 2008, Eurostat has asked member countries to report the proportion of full-time employees with earnings on the minimum wage and this measure will be used to measure the size of the spike at the minimum wage level. Also these data on the spike are unique, even if it should be noticed how they were not fully harmonized between the countries (Eurostat, personal communication). Given that the survey on undeclared work took place in May-June 2007 and that the question on underreporting of earnings referred to the last 12 months, I will use spike data for 2006. I will also use Eurostat data on the minimum monthly wage as a proportion of average monthly earnings in industry and services and I will refer to this measure as the Kaitz index.

Among the 27 countries that are members of the European Union, seven (the three Nordic countries, plus Austria, Cyprus, Germany, and Italy) do not have anything resembling a national minimum wage (see Eurostat 2007a, for the methodology used to calculate the minimum wage), while Eurostat does not report the proportion of full-time employees with earnings on the minimum wage for Belgium and Greece (Eurostat 2007b). Therefore, the analysis is conducted on the remaining 18 countries. This is clearly a small sample size and the results should be interpreted accordingly. However, despite their 
limitations, these are, to the best of my knowledge, the best available data to assess the relationship between the spike at the minimum wage and underreporting of earnings.

Table 1 reports some summary statistics for the main variables of interest. In Table 2, I present some simple regression results. I will explore the robustness of these results in section 3.1. Looking at Table 2, it emerges how, when considered in isolation, both the informal economy as proxied by the percentage of employees being paid cash-in-hand and the ratio of the minimum to average wage have an insignificant relationship with the size of the spike (columns 1 and 2). The Kaitz index and the spike in the wage distribution corresponding to the minimum wage are the two measures most commonly used to assess how binding the minimum wage is and one would expect to see a positive correlation between the two, even if they do not necessarily always move together (see Dolado et al. 1998, for a formal argument). However, this does not appear to be the case in the European context, unless one controls for informality. Indeed, when informality and the Kaitz index are considered together, the coefficients are statistically significant (column $3)$. Notice that the model that has been presented in section 2 predicts a positive correlation between the spike at the minimum wage and the size of the informal economy for a given productivity distribution and minimum wage. Thus, the inclusion of the Kaitz index in the regressions is theoretically justified. Eyeballing the graphs plotting the size of the spike against the size of the informal economy (left-hand side of Figure 1) and the size of the spike against the Kaitz index (right-hand side) gives indeed the impression of a positive correlation, with some notable outliers. In particular, looking at the relationship between the spike and the Kaitz index, countries like Romania and Latvia appear as outliers, with a big spike despite a low minimum wage relative to the average, while at the same time underreporting of earnings is widespread in these two countries. Looking at the relationship between the spike and the informal economy, France and Luxembourg are characterized by a very small informal economy and a big spike, but a minimum wage that is high relative to the average wage.

The size of the coefficient for the informal economy in column 3 implies that, when controlling for the size of the minimum wage relative to the average wage, an increase by $1 \%$ in the proportion of dependent employees answering affirmatively to the question on whether they have been paid cash-in-hand in the last 12 months is related to almost a $0.5 \%$

Table 1 Summary statistics

\begin{tabular}{lcccc}
\hline & Mean & Std. Dev. & Min & Max \\
\hline Spike & 5.62 & 4.46 & 0.96 & 15.10 \\
Informality Definition 1 & 6.89 & 6.26 & 1.00 & 23.00 \\
Informality Definition 2 & 2.96 & 4.09 & 0.01 & 16.19 \\
Informality Definition 3 & 2.54 & 3.17 & 0.00 & 11.04 \\
Informality Definition 4 & 4.94 & 5.78 & 0.00 & 20.47 \\
Informality Definition 5 & 9.61 & 7.83 & 1.00 & 30.00 \\
Kaitz Index & 40.00 & 5.76 & 30.20 & 50.40 \\
\hline
\end{tabular}

"Spike" is spike at minimum wage level in 2006 (except for the Netherlands: 2005) in \%.

"Informality" refers to the period 2006/2007 and is given by:

Def 1: \% of YES on question about employer paying cash-in-hand in the last 12 months;

Def 2: as in Def 1 multiplied by \% of gross yearly income in the main job paid cash-in-hand;

Def 3: as in Def 1 multiplied by \% of employees receiving cash-in-hand as part of remuneration for regular job;

Def 4: as in Def 3 including also employees receiving cash-in-hand for both regular job and overtime hours;

Def 5: as in Def 1 including also those refusing to answer the question;

"Kaitz Index" is given by the minimum monthly wage as a \% of average monthly earnings in industry and services for

2006 (except for France: 2007). 
Table 2 Regression results

\begin{tabular}{lccccccc}
\hline & $\mathbf{1}$ & $\mathbf{2}$ & $\mathbf{3}$ & $\mathbf{4}$ & $\mathbf{5}$ & $\mathbf{6}$ & $\mathbf{7}$ \\
\hline Informality & 0.23 & - & $0.48^{* *}$ & $0.67^{* *}$ & $0.93^{* *}$ & $0.50^{* *}$ & $0.36^{* *}$ \\
& $(0.17)$ & & $(0.18)$ & $(0.27)$ & $(0.34)$ & $(0.19)$ & $(0.15)$ \\
MW / AW & - & 0.17 & $0.47^{* *}$ & $0.42^{* *}$ & $0.44^{* *}$ & $0.44^{* *}$ & $0.45^{* *}$ \\
& & $(0.19)$ & $(0.20)$ & $(0.20)$ & $(0.19)$ & $(0.19)$ & $(0.20)$ \\
Constant & $4.05^{* *}$ & -1.09 & $-16.56^{*}$ & -13.17 & $-14.42^{*}$ & $-14.48^{*}$ & $-15.71^{*}$ \\
& $(1.55)$ & $(7.63)$ & $(8.76)$ & $(8.32)$ & $(8.08)$ & $(8.28)$ & $(8.92)$ \\
\hline $\mathrm{R}^{2}$ & 0.10 & 0.05 & 0.35 & 0.32 & 0.36 & 0.35 & 0.32
\end{tabular}

Obs.

18

a. Dependent variable is spike at minimum wage level in 2006 (except for the Netherlands: 2005).

b. The variable "Informality" refers to the period 2006/2007 and is given by (see note on Table 1 for details): Def 1 for columns 1) and 3), Def 2/3/4/5 for columns 4), 5), 6), 7), respectively.

c. The variable "MW/AW" is given by the minimum monthly wage as a proportion of average monthly earnings in industry and services for 2006 (except for France: 2007).

d. OLS estimation. Standard errors in parenthesis.

e. ${ }^{* * *}[* *](*)$ denote significance at $1,[5]$, and (10) percent level.

increase in the proportion of full-time employees with earnings on the minimum wage. I also use different measures of the informal economy, based on the additional survey questions administered to those receiving unreported earnings. In column 4, I use the product between the proportion of dependent employees receiving cash-in-hand and the proportion of gross yearly income paid cash-in-hand in the main job to these employees. This represents a measure of the proportion of the total wage bill that goes unreported in the economy, thus capturing both the "extensive" and "intensive" margins of underreporting. In column 5, I consider the proportion of dependent employees receiving cash-in-hand as part of remuneration for their regular job only, as opposed to overtime hours, while in column 6 I include also those receiving cash-in-hand for both their regular job and overtime. In some countries, for instance in Hungary, the statutory minimum wage relates

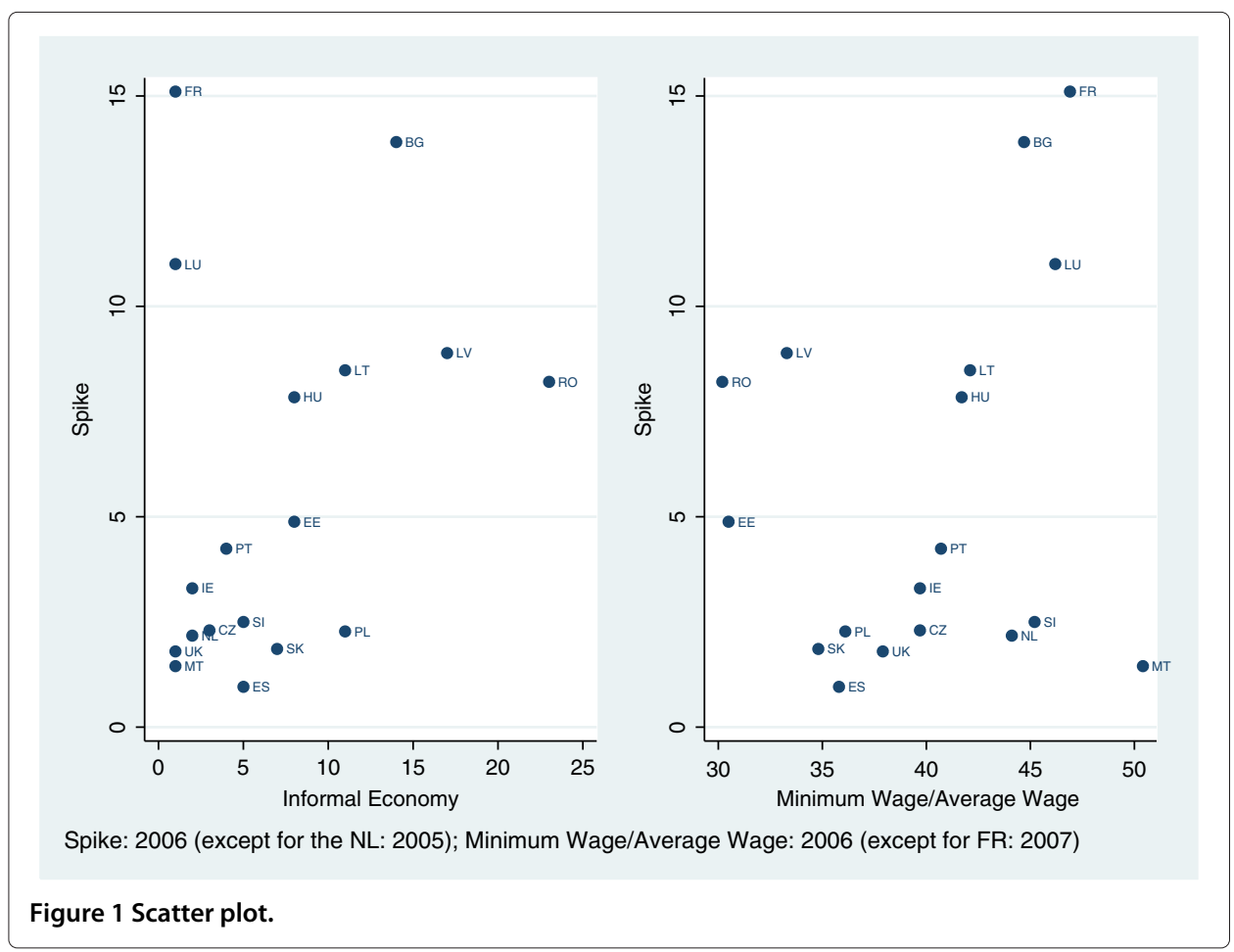


to gross monthly earnings net of overtime pay. In these cases, the minimum wage is not likely to represent a constraint to those underreporting remuneration only for overtime hours. The measures reported in columns 5 and 6 exclude them. Finally, considering the fact that undeclared work is a sensitive issue and people may be reluctant to admit it in a direct survey, in column 7 I also consider as receiving unreported pay those refusing to answer the question. Regardless of the specification, there appear to be a positive correlation between the size of the spike at the minimum wage level and the prevalence of underreporting of earnings in the economy, after controlling for the size of the minimum wage relative to the average ${ }^{8}$.

\subsection{Robustness}

To check for the robustness of this relationship, here I control for additional variables. Given the small sample size, I add to the regressions one variable at the time. Descriptive statistics for these variables are presented in Table 3, while the regression results in Tables 4, 5, 6 and 7. Regression results are presented for the five different definitions of informality discussed in the previous section. To facilitate the comparison, columns in Tables 4, 5, 6 and 7 are numbered to match the column in Table 2 using the same definition of informality.

Table 3 Robustness checks: summary statistics

\begin{tabular}{|c|c|c|c|c|}
\hline & Mean & Std. Dev. & Min & Max \\
\hline gdppc_eur & 18.93 & 17.30 & 3.40 & 71.80 \\
\hline gdppc_ppp & 21.46 & 12.94 & 9.00 & 64.00 \\
\hline activity & 68.79 & 5.09 & 57.60 & 77.40 \\
\hline unemployment & 7.51 & 2.71 & 4.40 & 13.90 \\
\hline temporary & 10.77 & 9.07 & 1.80 & 34.10 \\
\hline parttime & 11.71 & 10.32 & 1.80 & 45.80 \\
\hline hours & 38.13 & 2.74 & 30.70 & 41.60 \\
\hline lowsec & 33.26 & 16.42 & 16.40 & 72.40 \\
\hline tertiary & 18.94 & 6.45 & 9.60 & 27.70 \\
\hline spallp & 206.21 & 200.24 & 16.84 & 627.98 \\
\hline spallg & 0.82 & 0.56 & 0.11 & 2.10 \\
\hline unbp & 121.94 & 137.28 & 7.89 & 420.94 \\
\hline unbg & 0.48 & 0.45 & 0.05 & 1.40 \\
\hline placep & 4.68 & 6.30 & 0.00 & 23.16 \\
\hline placeg & 0.02 & 0.02 & 0.00 & 0.07 \\
\hline vocap & 10.78 & 16.47 & 0.00 & 58.80 \\
\hline vocag & 0.05 & 0.06 & 0.00 & 0.24 \\
\hline lowwagetrap_s & 38.59 & 17.90 & 17.30 & 75.00 \\
\hline lowwagetrap_c & 54.65 & 29.96 & 5.00 & 108.00 \\
\hline unemptrap & 73.91 & 11.38 & 43.00 & 88.00 \\
\hline $\operatorname{tax} 1 \_50$ & 17.57 & 6.16 & 6.82 & 28.67 \\
\hline one67nokids & 21.02 & 5.53 & 12.22 & 30.14 \\
\hline one67kids & 2.79 & 10.77 & -17.89 & 24.69 \\
\hline tax2_100 & 12.97 & 8.28 & -0.53 & 26.90 \\
\hline $\operatorname{tax} 2 \_130$ & 21.41 & 6.42 & 9.35 & 32.56 \\
\hline tax2_200 & 25.11 & 5.89 & 12.93 & 35.30 \\
\hline micro & 88.97 & 5.99 & 71.20 & 95.50 \\
\hline emp_micro & 26.48 & 6.69 & 14.02 & 38.57 \\
\hline
\end{tabular}

See variable list for definitions. Sample size is 18, except for "micro" and "emp_micro" where it is 16. 
Table 4 Robustness checks: regression results - general

\begin{tabular}{|c|c|c|c|c|c|}
\hline & 3 & 4 & 5 & 6 & 7 \\
\hline Informality & $0.67^{* * *}$ & $0.78^{* *}$ & $1.20^{* * *}$ & $0.67^{* * *}$ & $0.51^{* * *}$ \\
\hline MW/AW & $0.47^{* *}$ & $0.39^{*}$ & $0.42^{* *}$ & $0.42^{* *}$ & $0.44^{* *}$ \\
\hline gdppc_eur & 0.11 & 0.06 & 0.09 & 0.1 & 0.11 \\
\hline Informality & $0.65^{* * *}$ & $0.78^{* *}$ & $1.19^{* * *}$ & $0.66 * * *$ & $0.50^{* *}$ \\
\hline MW/AW & $0.47^{* *}$ & $0.40^{*}$ & $0.42^{* *}$ & $0.42^{* *}$ & $0.44^{* *}$ \\
\hline gdppc_ppp & 0.14 & 0.08 & 0.12 & 0.12 & 0.13 \\
\hline Informality & $0.57^{* *}$ & $0.76^{* *}$ & $1.09^{* *}$ & $0.59^{* *}$ & $0.42^{* *}$ \\
\hline MW/AW & $0.56^{* *}$ & $0.48^{*}$ & $0.52^{* *}$ & $0.52^{* *}$ & $0.52^{* *}$ \\
\hline activity & 0.16 & 0.11 & 0.16 & 0.16 & 0.14 \\
\hline Informality & $0.49^{* *}$ & $0.67^{* *}$ & $0.94^{* *}$ & $0.51^{* *}$ & $0.37^{* *}$ \\
\hline MW/AW & $0.46^{* *}$ & $0.42^{*}$ & $0.44^{* *}$ & $0.43^{* *}$ & $0.44^{*}$ \\
\hline unemployment & -0.12 & -0.04 & -0.08 & -0.10 & -0.11 \\
\hline Informality & $0.44^{* *}$ & $0.61^{*}$ & $0.86^{* *}$ & $0.46^{* *}$ & $0.34^{* *}$ \\
\hline MW/AW & $0.45^{* *}$ & $0.40^{*}$ & $0.42^{* *}$ & $0.42^{* *}$ & $0.43^{* *}$ \\
\hline temporary & -0.09 & -0.09 & -0.06 & -0.09 & -0.12 \\
\hline Informality & $0.47^{* *}$ & $0.63^{* *}$ & $0.90^{* *}$ & $0.48^{* *}$ & $0.36^{*}$ \\
\hline MW/AW & $0.47^{* *}$ & $0.43^{* *}$ & $0.44^{* *}$ & $0.44^{* *}$ & $0.45^{* *}$ \\
\hline parttime & -0.01 & -0.06 & -0.02 & -0.03 & 0.00 \\
\hline Informality & $0.54^{* *}$ & $0.65^{*}$ & $0.99^{* *}$ & $0.54^{* *}$ & $0.41^{*}$ \\
\hline MW/AW & $0.47^{* *}$ & $0.43^{*}$ & $0.44^{* *}$ & $0.43^{* *}$ & $0.44^{* *}$ \\
\hline hours & -0.19 & 0.06 & -0.11 & -0.12 & -0.20 \\
\hline Informality & $0.46^{* *}$ & $0.67^{* *}$ & $0.91^{* *}$ & $0.49^{* *}$ & $0.36^{* *}$ \\
\hline MW/AW & $0.51^{* *}$ & $0.49^{* *}$ & $0.50^{* *}$ & $0.49^{* *}$ & $0.51^{* *}$ \\
\hline lowsec & -0.04 & -0.06 & -0.05 & -0.05 & -0.06 \\
\hline Informality & $0.61^{* * *}$ & $0.86^{* *}$ & $1.16^{* * *}$ & $0.63^{* * *}$ & $0.48^{* * *}$ \\
\hline MW/AW & $0.55^{* *}$ & $0.49^{* *}$ & $0.51^{* *}$ & $0.51^{* *}$ & $0.53^{* *}$ \\
\hline tertiary & 0.24 & 0.23 & 0.22 & 0.22 & 0.24 \\
\hline
\end{tabular}

See variable list for definitions. Footnotes $a, b, c$, e in Table 2 apply also here. OLS estimation. All regressions include a constant. Sample size is 18.

One could think that less developed countries have more informality, for instance because of weaker institutions, and at the same time a higher spike, for instance because of a more right-skewed productivity distribution, with many unskilled workers, and this could be driving the correlation. However, controlling for GDP per capita (expressed either in euro or in purchasing power standard. See Table 4), the correlation between the size of the spike and the various measures of informality appears to be even stronger. Thus, it does not appear that this correlation is driven by differences in the level of economic development ${ }^{9}$. Controlling for various labour market variables like the activity rate, the unemployment rate, the share of employees with temporary contracts, the share of part-time employment, or the average number of weekly hours, does not change the picture. As the model predicts a positive correlation between the spike and informality for a given productivity distribution, I control for two variables related to it, namely the percentage of working age people with lower secondary education and the percentage with tertiary education. Also in these cases, the picture remains unchanged.

Next, I consider various measures of spending on the unemployed. Unemployment benefits may have an important impact on the shape of the wage distribution. It would 
Table 5 Robustness checks: regression results - social spending

\begin{tabular}{|c|c|c|c|c|c|}
\hline & 3 & 4 & 5 & 6 & 7 \\
\hline Informality & $0.67^{* * *}$ & $0.79^{* * *}$ & $1.26^{* * *}$ & $0.68^{* * *}$ & $0.46^{* *}$ \\
\hline MW/AW & $0.47^{* *}$ & $0.39^{*}$ & $0.42^{* *}$ & $0.42^{* *}$ & $0.43^{* *}$ \\
\hline spallp & $0.01^{*}$ & 0.01 & 0.01 & 0.01 & 0.01 \\
\hline Informality & $0.57^{* *}$ & $0.73^{* *}$ & $1.13^{* *}$ & $0.60^{* *}$ & $0.38^{* *}$ \\
\hline MW/AW & $0.48^{* *}$ & $0.41^{*}$ & $0.44^{* *}$ & $0.44^{* *}$ & $0.44^{*}$ \\
\hline spallg & 1.83 & 1.06 & 2.05 & 1.86 & 0.88 \\
\hline Informality & $0.60^{* * *}$ & $0.73^{* *}$ & $1.14^{* * *}$ & $0.62^{* *}$ & $0.43^{* *}$ \\
\hline MW/AW & $0.45^{* *}$ & $0.39^{*}$ & $0.41^{* *}$ & $0.41^{*}$ & $0.42^{*}$ \\
\hline unbp & 0.01 & 0.01 & 0.01 & 0.01 & 0.01 \\
\hline Informality & $0.54^{* *}$ & $0.70^{* *}$ & $1.05^{* *}$ & $0.56^{* *}$ & $0.38^{* *}$ \\
\hline MW/AW & $0.46^{* *}$ & $0.41^{*}$ & $0.42^{* *}$ & $0.42^{* *}$ & $0.43^{*}$ \\
\hline unbg & 1.89 & 0.94 & 1.99 & 1.88 & 1.16 \\
\hline Informality & $0.45^{* *}$ & $0.62^{* *}$ & $0.88^{* *}$ & $0.47^{* *}$ & $0.34^{* *}$ \\
\hline MW/AW & $0.47^{* *}$ & $0.42^{*}$ & $0.44^{* *}$ & $0.44^{* *}$ & $0.45^{* *}$ \\
\hline placep & -0.13 & -0.13 & -0.14 & -0.13 & -0.15 \\
\hline Informality & $0.51^{* *}$ & $0.67^{* *}$ & $0.98^{* *}$ & $0.52^{* *}$ & $0.38^{* *}$ \\
\hline MW/AW & $0.51^{* *}$ & $0.44^{* *}$ & $0.48^{* *}$ & $0.47^{* *}$ & $0.48^{* *}$ \\
\hline placeg & -34.29 & -21.42 & -34.57 & -30.61 & -32.51 \\
\hline Informality & $0.46^{* *}$ & $0.63^{*}$ & $0.90^{* *}$ & $0.48^{* *}$ & $0.33^{*}$ \\
\hline MW/AW & $0.46^{*}$ & $0.40^{*}$ & $0.43^{*}$ & $0.42^{*}$ & $0.41^{*}$ \\
\hline vocap & -0.01 & -0.02 & -0.01 & -0.01 & -0.04 \\
\hline Informality & $0.45^{* *}$ & $0.63^{*}$ & $0.88^{* *}$ & $0.47^{* *}$ & $0.34^{* *}$ \\
\hline MW/AW & $0.43^{*}$ & $0.39^{*}$ & $0.41^{*}$ & $0.41^{*}$ & $0.39^{*}$ \\
\hline vocag & -7.61 & -7.2 & -7.18 & -7.26 & -13.84 \\
\hline
\end{tabular}

See variable list for definitions. Footnotes a, b, c, e in Table 2 apply also here. OLS estimation. All regressions include a constant. Sample size is 18.

be straightforward to extend the model so that workers decide whether to participate in the formal labour market by comparing their income when formally working (albeit underreporting part of their earnings) to their income when working underground or not working at all, thus possibly receiving unemployment benefits. Moreover, in search models of the labour market, the outside option, including unemployment benefits, is an important determinant of the labour force participation decision and of the wage bargaining process (see for instance Ahn et al. 2011, for a simple search model with endogenous labour force participation giving rise to a spike at the minimum wage level). Beside having an impact on the wage distribution, benefits for the unemployed could also have an impact on informality, as with high benefits workers may be more inclined to work underground. To see whether this indeed matters, I control in Table 5 for total spending on the unemployed in purchasing power standard per capita or as a percentage of GDP. I also look at spending, using the same two types of measure, devoted to unemployment benefits, to placement services and job search assistance, and to vocational training. Unemployment benefits may affect the relationship between the spike and underreporting through the mechanism described above. Placement services and job search assistance may have an impact on the quality of matches between job seekers and firms, and thus potentially also on the distribution of earnings and, being available only for formal jobs, on the size of the informal economy. Finally, vocational training may influence the productivity distribution. None of these factors has an impact on the relationship between 
Table 6 Robustness checks: regression results - taxes

\begin{tabular}{|c|c|c|c|c|c|}
\hline & 3 & 4 & 5 & 6 & 7 \\
\hline Informality & $0.45^{* *}$ & $0.62^{* *}$ & $0.88^{* *}$ & $0.47^{* *}$ & $0.34^{*}$ \\
\hline MW/AW & $0.46^{* *}$ & $0.42^{*}$ & $0.43^{* *}$ & $0.43^{* *}$ & $0.44^{*}$ \\
\hline lowwagetrap_s & -0.03 & -0.04 & -0.02 & -0.03 & -0.02 \\
\hline Informality & $0.49^{* *}$ & $0.68^{* *}$ & $0.96^{* *}$ & $0.51^{* *}$ & $0.38^{* *}$ \\
\hline MW/AW & $0.46^{* *}$ & $0.41^{*}$ & $0.43^{* *}$ & $0.43^{* *}$ & $0.44^{*}$ \\
\hline lowwagetrap_c & 0.01 & 0.01 & 0.01 & 0.01 & 0.02 \\
\hline Informality & $0.43^{* *}$ & $0.59^{*}$ & $0.85^{* *}$ & $0.45^{* *}$ & $0.32^{*}$ \\
\hline MW/AW & $0.40^{*}$ & 0.35 & $0.38^{*}$ & $0.37^{*}$ & $0.38^{*}$ \\
\hline unemptrap & 0.08 & 0.09 & 0.10 & 0.09 & 0.09 \\
\hline Informality & $0.51^{* *}$ & $0.70^{* *}$ & $0.95^{* *}$ & $0.52^{* *}$ & $0.36^{* *}$ \\
\hline MW/AW & $0.47^{* *}$ & $0.42^{*}$ & $0.44^{* *}$ & $0.44^{* *}$ & $0.45^{* *}$ \\
\hline tax1_50 & -0.06 & -0.05 & -0.03 & -0.05 & -0.01 \\
\hline Informality & $0.48^{* *}$ & $0.67^{* *}$ & $0.92^{* *}$ & $0.50^{* *}$ & $0.35^{* *}$ \\
\hline MW/AW & $0.47^{* *}$ & $0.42^{*}$ & $0.44^{* *}$ & $0.44^{* *}$ & $0.45^{* *}$ \\
\hline tax1_67 & 0.00 & 0.00 & 0.04 & 0.02 & 0.05 \\
\hline Informality & $0.48^{* *}$ & $0.68^{* *}$ & $0.93^{* *}$ & $0.52^{* *}$ & $0.35^{* *}$ \\
\hline MW/AW & $0.47^{* *}$ & $0.42^{*}$ & $0.44^{* *}$ & $0.44^{* *}$ & $0.45^{* *}$ \\
\hline tax1_67kids & -0.01 & -0.01 & 0.00 & -0.02 & 0.02 \\
\hline Informality & $0.50^{* *}$ & $0.67^{* *}$ & $0.93^{* *}$ & $0.52^{* *}$ & $0.36^{* *}$ \\
\hline MW/AW & $0.48^{* *}$ & $0.42^{*}$ & $0.44^{* *}$ & $0.45^{* *}$ & $0.45^{*}$ \\
\hline tax2_100kids & -0.02 & 0.00 & 0.00 & -0.02 & 0.00 \\
\hline Informality & $0.50^{* *}$ & $0.69^{* *}$ & $0.94^{* *}$ & $0.51^{* *}$ & $0.37^{* *}$ \\
\hline MW/AW & $0.48^{* *}$ & $0.42^{*}$ & $0.44^{* *}$ & $0.44^{* *}$ & $0.45^{* *}$ \\
\hline tax2_130 & -0.11 & -0.1 & -0.06 & -0.08 & -0.08 \\
\hline Informality & $0.48^{* *}$ & $0.67^{* *}$ & $0.93^{* *}$ & $0.50^{* *}$ & $0.36^{* *}$ \\
\hline MW/AW & $0.48^{* *}$ & $0.43^{*}$ & $0.44^{* *}$ & $0.44^{* *}$ & $0.45^{* *}$ \\
\hline $\operatorname{tax} 2 \_200$ & -0.05 & -0.06 & 0.00 & -0.02 & -0.04 \\
\hline
\end{tabular}

See variable list for definitions. Footnotes $a, b, c, e$ in Table 2 apply also here. OLS estimation. All regressions include a constant. Sample size is 18.

the spike and informality. The same is true when I include also the unemployment rate as a control (results not reported).

In the previous section I have shown in a stylized model of the labour market with underreporting of earnings how the positive correlation between informality and the spike emerges because of their common dependence on the strength of fiscal enforcement. One could argue that, rather than enforcement, it could be the case that it is the tax rate that is driving the correlation, with countries where tax rates on labour earnings are

Table 7 Robustness checks: regression results - small firms

\begin{tabular}{lccccc}
\hline & $\mathbf{3}$ & $\mathbf{4}$ & $\mathbf{5}$ & $\mathbf{6}$ & $\mathbf{7}$ \\
\hline Informality & $0.53^{* * *}$ & $0.74^{* * *}$ & $1.05^{* * *}$ & $0.56^{* * *}$ & $0.43^{* * *}$ \\
MW/AW & $0.56^{* * *}$ & $0.55^{* *}$ & $0.55^{* * *}$ & $0.55^{* * *}$ & $0.56^{* * *}$ \\
micro & -0.15 & -0.18 & -0.10 & -0.16 & $-0.23^{*}$ \\
\cline { 2 - 6 } Informality & $0.52^{* * *}$ & $0.70^{* * *}$ & $1.05^{* * *}$ & $0.55^{* * *}$ & $0.42^{* * *}$ \\
MW/AW & $0.51^{* * *}$ & $0.47^{* *}$ & $0.52^{* * *}$ & $0.50^{* *}$ & $0.49^{* *}$ \\
emp_micro & -0.09 & -0.08 & -0.02 & -0.07 & -0.16 \\
\hline
\end{tabular}

See variable list for definitions. Footnotes a, b, c, e in Table 2 apply also here. OLS estimation. All regressions include a constant. Sample size is 16 . 
higher having both more informality and larger spikes. In the model the size of the spike and the size of the underground economy do not depend on the tax rate. This is due to the standard assumption that the fine is proportional to the amount evaded. The tax rate would instead matter with a fine proportional to the undeclared amount (as in Allingham and Sandmo 1972) or some fixed cost in case of detection. To see whether the relationship between the spike and informality is driven by the tax rate, I add several measures of the tax rate as control variables (see Table 6). The most relevant one for people partially underreporting their earnings is the so called "low wage trap", measuring the percentage of gross earnings which is taxed away through the combined effects of income taxes, social security contributions and any withdrawal of benefits when gross earnings increase from $33 \%$ to $67 \%$ of the average wage, both for single persons without children and for one-earner couples with two children. I also include as control the "unemployment trap", measuring the percentage of gross earnings which is taxed away through higher tax and social security contributions and the withdrawal of unemployment, and other, benefits when an unemployed person returns to employment. This is particularly relevant for people deciding whether to be formally employed or not. Eurostat measures this quantity for a single person without children earning $67 \%$ of the average wage when in work. I also add several other measures of the tax rate, defined as the income tax on gross wage earnings plus the employee's social security contributions less universal cash benefits, expressed as a percentage of gross wage earnings, for several situations (single person without children earning $50 \%$ or $67 \%$ of the average wage; single parent with two children earning $67 \%$ of the average wage; one-earner married couple with two children earning $100 \%$ of the average wage; two-earner married couple, one at $100 \%$, the other at $33 \%$ or at $100 \%$ of the average wage, with no children). In all specification the tax rate is not significant, while the different measures of informality and the Kaitz index maintain their statistical significance.

Another possible alternative mechanism to explain the correlation between the spike and informality involves the importance of small firms in the economy. Namely, small firms may be more likely to pay the minimum wage, because their productivity is generally lower and they are less unionized, and also more likely to underreport to fiscal authorities, because they are less subject to audits. Thus, countries with more small firms may tend to have both a higher spike and a bigger informal economy. This, however, turns out not to be the case when looking at the European labour markets considered here. Adding the share of micro enterprises (defined as those with less than 10 employees) in the total population of enterprises or their relative share of the workforce does not affect the positive correlation between the spike and informality ${ }^{10}$ (see Table 7).

The evidence that has been presented shows a positive correlation between the size of the spike at the minimum wage and informality. This is consistent with the model. Due to the small sample size this evidence cannot be considered conclusive, but, given the difficulties in finding suitable data, it is, to the best of my knowledge, the best evidence available. In the next section, I will conclude by discussing some policy implications.

\section{Conclusions}

In this paper, I have highlighted the fact that the minimum wage affects compliance with fiscal regulation and has therefore a potential role in enforcement. What are the implications for minimum wage policy? A first thing to notice is that, in contexts where 
underreporting is pervasive, it would be incorrect to argue that a high proportion of the workforce earning the minimum wage is an indicator of the minimum wage being particularly binding from a labour market perspective. Thus, somebody calling for a reduction in the minimum wage, for instance because there is high unemployment in the economy, and claiming that a high spike indicates that the minimum wage is indeed too high given the productivity distribution, may be quite off the mark in a country where envelope wages are common.

The analysis also suggests that, among the many other considerations usually highlighted in the literature, when designing a minimum wage policy, its implications for underreporting should be taken into account. In particular, if there are variables that are easily observable by the tax authority, difficult to manipulate, and linked to earnings (e.g. education, sector, occupation), then it would make sense from an enforcement perspective to differentiate the minimum wage accordingly. In this way, it would be possible to fix a higher minimum, and thus ensure higher compliance, for workers belonging to categories with higher earnings, without pricing truly low skilled workers out of the official labour market. Examples of such arrangements exist in Hungary, where there is a threetier minimum wage system linked to education, and in Bulgaria, with social security contribution paid on minima differentiated according to sector and occupation (Tonin 2013).

\section{Appendix}

\section{Proofs}

\section{Proof of Proposition 1}

A decrease in enforcement parameters, i.e. an increase in $\alpha$, induces the minimum wage to be declared by some workers previously declaring more, thereby increasing the size of the spike. If enforcement is sufficiently weak, i.e. if $1 / 2<\alpha<1$, an additional effect plays a role, as some workers previously declaring the minimum wage prefer to go into the black economy, thus reducing the size of the spike. In this case

$$
\frac{\partial S}{\partial \alpha}>0 \Leftrightarrow g\left(\frac{\varpi}{1-a}\right)>\frac{1}{2} g\left(\frac{\varpi}{2(1-a)}\right) .
$$

Assuming that the distribution of productivity is single peaked, the above condition is satisfied if the minimum wage is binding for workers with productivity lower than the mode. The analysis can also be conducted in terms of the size of the spike relative to the size of the officially employed workforce, where the latter is given by:

$$
L=\int_{\varpi \max \{1 /(2-2 \alpha), 1\}}^{\bar{y}} g(y) d y .
$$

The condition for the spike relative to the officially employed workforce, $S / L$, to increase with $\alpha$ is looser than (3), as the size of the officially employed workforce is not increasing with $\alpha$. In particular, when $\alpha \leq \frac{1}{2}$,

$$
\frac{S}{L}=\frac{\int_{\varpi}^{\varpi /(1-a)} g(y) d y .}{\int_{\varpi}^{\bar{y}} g(y) d y}
$$

and

$$
\frac{\partial S / L}{\partial \alpha}=\frac{\varpi g(\varpi /(1-a))}{(1-a)^{2} \int_{\varpi}^{\bar{y}} g(y) d y}>0 .
$$


When $\frac{1}{2}<\alpha<1$, then

$$
\frac{S}{L}=\frac{\int_{\varpi /(2-2 \alpha)}^{\varpi /(1-a)} g(y) d y}{\int_{\varpi /(2-2 \alpha)}^{\bar{y}} g(y) d y} .
$$

Given that

$$
\frac{\partial S}{\partial \alpha}=\frac{\varpi}{(1-a)^{2}} g(\varpi /(1-a))-\frac{\varpi}{2(1-\alpha)^{2}} g(\varpi /(2-2 \alpha))
$$

and that

$$
\frac{\partial L}{\partial \alpha}=-\frac{\varpi}{2(1-\alpha)^{2}} g(\varpi /(2-2 \alpha))
$$

then

$$
\begin{aligned}
\frac{\partial S / L}{\partial \alpha}= & \frac{\left(\begin{array}{c}
{\left[\frac{\varpi}{(1-a)^{2}} g(\varpi /(1-a))-\frac{\varpi}{2(1-\alpha)^{2}} g(\varpi /(2-2 \alpha))\right] \int_{\varpi /(2-2 \alpha)}^{\bar{y}} g(y) d y} \\
+\frac{\varpi}{2(1-\alpha)^{2}} g(\varpi /(2-2 \alpha)) \int_{\varpi /(2-2 \alpha)}^{\varpi /(1-a)} g(y) d y
\end{array}\right)}{\left[\int_{\varpi /(2-2 \alpha)}^{\bar{y}} g(y) d y\right]^{2}} \\
& >0 \Leftrightarrow g(\varpi /(1-a))>\frac{1}{2} g(\varpi /(2-2 \alpha)) \frac{\int_{\varpi /(1-a)}^{\bar{y}} g(y) d y}{\int_{\varpi /(2-2 \alpha)}^{\bar{y}} g(y) d y},
\end{aligned}
$$

where

$$
\frac{\int_{\varpi /(1-a)}^{\bar{y}} g(y) d y}{\int_{\varpi /(2-2 \alpha)}^{\bar{y}} g(y) d y}<1
$$

\section{Proof of Proposition 2}

First, notice that when workers with a productivity below the minimum wage work in the black market, i.e. when $\alpha \geq t / 2$, the size of the informal economy is given by:

$$
U=\underbrace{\int_{\mathrm{y}}^{\varpi \max \{1 /(2-2 \alpha), 1\}} y g(y) d y}_{\text {black economy }}+\underbrace{\int_{\varpi \max \{1 /(2-2 \alpha), 1\}}^{\varpi /(1-a)}(y-\varpi) g(y) d y+\alpha \int_{\varpi /(1-a)}^{\bar{y}} y g(y) d y}_{\text {underreporting }} .
$$

A decrease in enforcement, i.e. an increase in $\alpha$, increases the size of the informal economy as workers unaffected by the minimum wage evade more. Moreover, when enforcement is already low, i.e. $1 / 2<\alpha<1$, some workers previously declaring the minimum wage go into the black economy, thereby further increasing informality. The size of the informal economy relative to the economy as a whole, $U / Y$, or relative to the size of the formal economy, $U /(Y-U)$, is also of interest. When $\alpha \geq t / 2$, the size of the economy is given by $Y=\int_{\underline{y}}^{\bar{y}} y g(y) d y$ and does not depend on $\alpha$. Thus, the derivatives of $U$, $U / Y, U /(Y-U)$ w.r.t. $\alpha$ all have the same sign.

When workers with productivity below the minimum wage withdraw from the labour market, i.e. when $\alpha<t / 2$, there is no black market, thus the size of the underground economy is given by the last two terms in expression (5), representing, respectively, underreporting by workers declaring the minimum wage and underreporting by workers declaring more than the minimum. Also in this case does a decrease in enforcement, i.e. an increase in $\alpha$, increase the size of the informal economy as workers unaffected by the minimum wage evade more. Notice that there is a discontinuity in the size of the informal economy at $\alpha=t / 2$. When enforcement parameters decrease (i.e. $\alpha$ increases), the size 
of the informal economy jumps up discretely as workers previously withdrawn from the labour market enter into the black market. This jump goes in the same direction as the derivative, so it is possible to state that the size of the informal economy always increases as enforcement decreases. The same is true if I consider the size of the informal economy relative to the whole economy, $U / Y$, or relative to the formal economy, $U /(Y-U)$. In particular, when $0<\alpha<\frac{t}{2}$,

$$
U=\int_{\varpi}^{\varpi /(1-a)}(y-\varpi) g(y) d y+\alpha \int_{\varpi /(1-a)}^{\bar{y}} y g(y) d y,
$$

then

$$
\begin{aligned}
\frac{\partial U}{\partial \alpha}= & \frac{\varpi}{(1-a)^{2}}(\varpi /(1-a)-\varpi) g(\varpi /(1-a)) \\
& +\int_{\varpi /(1-a)}^{\bar{y}} y g(y) d y+\alpha \frac{\varpi}{(1-a)^{2}} \varpi /(1-a) g(\varpi /(1-a)) \\
= & \int_{\varpi /(1-a)}^{\bar{y}} y g(y) d y>0 .
\end{aligned}
$$

When $\frac{t}{2} \leq \alpha \leq \frac{1}{2}$

$$
U=\int_{\underline{\mathbf{y}}}^{\varpi} y g(y) d y+\int_{\varpi}^{\varpi /(1-a)}(y-\varpi) g(y) d y+\alpha \int_{\varpi /(1-a)}^{\bar{y}} y g(y) d y,
$$

and, given that $\int_{\mathrm{y}}^{\sigma} y g(y) d y$ does not depend on $\alpha$, the derivative is the same as in the previous case. At $\alpha=\frac{t}{2}$ the size of the underground economy jumps up by $\int_{\underline{\mathrm{y}}}^{\varpi} y g(y) d y$. When $\frac{1}{2}<\alpha<1$,

$$
U=\int_{\underline{\underline{y}}}^{\varpi /(2-2 \alpha)} y g(y) d y+\int_{\varpi /(2-2 \alpha)}^{\varpi /(1-a)}(y-\varpi) g(y) d y+\alpha \int_{\varpi /(1-a)}^{\bar{y}} y g(y) d y,
$$

then

$$
\begin{aligned}
\frac{\partial U}{\partial \alpha}= & \frac{\varpi}{2(1-\alpha)^{2}} \frac{\varpi}{(2-2 \alpha)} g\left(\frac{\varpi}{(2-2 \alpha)}\right)-\frac{\varpi}{2(1-\alpha)^{2}}\left(\frac{\varpi}{(2-2 \alpha)}-\varpi\right) g\left(\frac{\varpi}{(2-2 \alpha)}\right)+ \\
& +\frac{\varpi}{(1-a)^{2}}(\varpi /(1-a)-\varpi) g(\varpi /(1-a)) \\
& +\int_{\varpi /(1-a)}^{\bar{y}} y g(y) d y+\alpha \frac{\varpi}{(1-a)^{2}} \varpi /(1-a) g(\varpi /(1-a)) \\
= & \frac{\varpi^{2}}{2(1-\alpha)^{2}} g\left(\frac{\varpi}{(2-2 \alpha)}\right)+\int_{\varpi /(1-a)}^{\bar{y}} y g(y) d y>0 .
\end{aligned}
$$

When $0<\alpha<\frac{t}{2}$, the size of the economy is given by $Y=\int_{\varpi}^{\bar{y}} y g(y) d y$. When $\alpha \geq \frac{t}{2}$, the size of the economy is given by $Y=\int_{\underline{y}}^{\bar{y}} y g(y) d y$. In both case, it does not depend on $\alpha$. As

$$
\frac{\partial \frac{U}{Y-U}}{\partial \alpha}>0 \Leftrightarrow \frac{\partial U}{\partial \alpha}(Y-U)-\frac{\partial(Y-U)}{\partial \alpha} U>0 \Leftrightarrow \frac{\partial U}{\partial \alpha}(Y-U)+\frac{\partial U}{\partial \alpha} U>0 \Leftrightarrow \frac{\partial U}{\partial \alpha}>0,
$$

the derivatives of $U, U / Y, U /(Y-U)$ w.r.t. $\alpha$ all have the same sign. 


\section{Variable list}

Here I provide a definition for all the variables used in the robustness checks. The source is EUROSTAT. The year is 2006 unless otherwise indicated.

- gdppc_eur: GDP per capita in Euro in thousands.

- gdppc_ppp: GDP per capita in Purchasing Power Standard in thousands.

- activity: Activity rate (15 to 64 years).

- unemployment: Unemployment rate, annual average (\%).

- temporary: Temporary employees as percentage of the total number of employees (\%) - From 15 to 64 years.

- parttime: Part-time employment as percentage of the total employment (\%) - From 15 to 64 years.

- hours: Average number of actual weekly hours of work in main job (hours) Employees - All NACE.

- lowsec: Persons with lower secondary education attainment (\%) - From 15 to 64 years.

- tertiary: Persons with tertiary education attainment (\%) - From 15 to 64 years.

The following 8 variables refer to various measures of spending on the unemployed.

- spallp: Social protection benefits spent on the unemployment function. In Purchasing Power Standard per inhabitant.

- spallg: Same as above expressed as Percentage of GDP.

- unbp: Full unemployment benefits refer to benefits compensating for loss of earnings where a person is capable of working and available for work but is unable to find suitable employment, including persons who had not previously been employed. In Purchasing Power Standard per inhabitant.

- unbg: Same as above expressed as Percentage of GDP.

- placep: Placement services and job search assistance covers intermediation, information and career guidance services provided by job-placement/employment agencies. In Purchasing Power Standard per inhabitant. Data for Poland are for 2005.

- placeg: Same as above expressed as Percentage of GDP.

- vocap: Vocational training - payments made by social security funds or public agencies to institutions which provide professional training to people without a job or at risk of losing their job shortly to develop their potential for further employment. In Purchasing Power Standard per inhabitant.

- vocag: Same as above expressed as Percentage of GDP.

- lowwagetrap_s: low wage trap, measuring the percentage of gross earnings which is taxed away through the combined effects of income taxes, social security contributions and any withdrawal of benefits when gross earnings increase from $33 \%$ to $67 \%$ of AW. Referring to single persons without children.

- lowwagetrap_c: As above, referring to one-earner married couple, at 33\% of AW, with two children.

- unemptrap: unemployment trap, measuring the percentage of gross earnings which is taxed away through higher tax and social security contributions and the withdrawal of unemployment, and other, benefits when an unemployed person returns to employment. This structural indicator is available only for single persons without children earning $67 \%$ of the AW when in work. 
The following 6 variables refer to the tax rate, defined as the income tax on gross wage earnings plus the employee's social security contributions less universal cash benefits, expressed as a percentage of gross wage earnings. The specific situation is specified in the definition of each variable. AW stands for Average Wage.

- tax1_50: Single parent without children, with earnings at 50\% of AW.

- one67nokids: Single parent without children, with earnings at $67 \%$ of AW.

- one67kids: Single parent with 2 children, with earnings at $67 \%$ of AW.

- tax2_100: One-earner married couple, with earnings at 100\% of AW, with two children.

- tax2_130: Two-earner married couple, with earnings one at 100\%, the other at 33\% of AW, with no children.

- tax2_200: Two-earner married couple, with earnings one at $100 \%$, the other at $100 \%$ of AW, with no children.

- micro: share of micro enterprises in the total population of enterprises active in the non-financial business economy. Data for France and Malta are not available. Data are for 2008.

- emp_micro: micro enterprises relative share of the non-financial business economy workforce. Data for France and Malta are not available. Data are for 2008.

\section{Endnotes}

${ }^{1}$ Reviews on the impact of the minimum wage are provided in Brown (1999) and Neumark and Wascher (2008).

${ }^{2}$ All data are from Eurostat. Details are provided in Section 3.

${ }^{3}$ See Andreoni et al. (1998) or Slemrod and Yitzhaki (2002) for surveys on tax evasion and Schneider and Enste (2000) for a survey on the shadow economy.

${ }^{4}$ An exception is Tonin (2011), where I study the implications of the minimum wage for underreporting in the Hungarian context.

${ }^{5}$ The assumption is that enforcement is strong enough so that $\alpha \in(0,1)$.

6"Was this income part of the remuneration for your regular work, was it payment for overtime hours or was it both?"

7“Approximately which percentage share of your gross yearly income in your main job did you get this way?"

${ }^{8}$ For specifications 3 to 7 , a Shapiro-Wilk test fails to reject the null that the distribution of residuals is normal ( $p$-value for specification $3: 0.605 ; 4: 0.386 ; 5: 0.588 ; 6: 0.735 ; 7: 0.801$ ), while this is not the case for specifications 1 ( $p$-value 0.006$)$ and 2 ( $p$-value 0.073$)$. This provides some reassurance about the validity of the test statistics on which the claim of a significant correlation is based.

${ }^{9}$ Notice that, despite considering only countries within the EU, the dispersion in terms of GDP per capita is not negligible.

${ }^{10}$ In particular, I use the share of micro enterprises in the total population of enterprises active in the non-financial business economy, and the micro enterprises relative share of the non-financial business economy workforce for 2008. Data on France and Malta are not available. The source is Eurostat. 


\begin{abstract}
Acknowledgements
I thank Eurostat for providing the data on the proportion of full-time employees with earnings on the minimum wage. Comments and suggestions by several seminar and conference participants have been most helpful. Financial support
\end{abstract} from Jan Wallander's and Tom Hedelius' Research Foundations is gratefully acknowledged.

Responsible editor: Alan Barrett

Received: 10 November 2012 Accepted: 23 January 2013

Published: 4 March 2013

\title{
References
}

Acemoglu D, Pischke JS (2003) Minimum wages and on-the-job training. Res Labor Econ 22: 159-202

Ahn T, Arcidiacono P, Wessels W (2011) The distributional impacts of minimum wage increases when both labor supply and labor demand are endogenous. J Bus Econ Stat 29(1): 12-23

Allingham MG, Sandmo A (1972) Income tax evasion: a theoretical analysis. J Public Econ 1(3-4): 323-338

Andreoni J, Erard B, Feinstein J (1998) Tax compliance. J Econ Lit 36: 818-860

Bosch M, Manacorda M (2010) Minimum wages and earnings inequality in urban Mexico. Am Econ J Appl Econ 2: 128-149

Brown C (1999) Minimum wages, employment, and the distribution of income. Handb Labor Econ 3: 2101-2163

De Fraja G (1999) Minimum wage legislation, productivity and employment. Economica 66: 473-488

Dolado J, Kramarz F, Machin S, Manning A, Margolis D, Teulings C (1998) The economic impact of minimum wages in Europe. Econ Policy 11:318-372

European Commission (2004) Undeclared work in an enlarged union. Directorate-general for employment and social affairs. European Communities, Luxembourg

European Commission (2007) Undeclared work in the European union. Special Eurobarometer 284. European Communities, Luxembourg

Eurostat (2007a) Minimum wages 2007. Statistics in focus Ů Population and social conditions Ů 71/2007. European Communities, Luxembourg

Eurostat (2007b) Statutory minimum wages in euro varied by one to seventeen across the EU. News Release 85/2007. European Communities, Luxembourg

Flinn CJ (2006) Minimum wage effects on labor market outcomes under search, matching, and endogenous contact rates. Econometrica 74(4): 1013-1062

Gorodnichenko Y, Martinez-Vazquez J, Sabirianova Peter K (2009) Myth and reality of flat tax reform: Micro estimates of tax evasion and productivity response in Russia. J Pol Econ 117(3): 504-554

Lemos S (2009) Minimum wage effects in a developing country. Labour Econ 16: 224-237

Maloney WF, Nuñez Mendez J (2004) Measuring the impact of minimum wages: evidence from Latin America. In:

Heckman JJ Pagés C (eds) Law and employment: lessons from Latin American and the Caribbean. University of Chicago Press, Chicago

Manning A (2003) Monopsony in motion: imperfect competition in labor markets. Princeton University Press, Princeton McIntyre F (2009) An empirical model of illegal work. mimeo

Neumark D, Wascher W (2008) Minimum wages. MIT Press, Cambridge

Petrova A (2005) Wages: on the payroll or under the Table?. Public Opinion Foundation, Moscow

Schneider F, Enste D (2000) Shadow economies: size, causes, and consequences. J Econ Lit 38(1): 77-114

Slemrod J, Yitzhaki S (2002) Tax avoidance, evasion, and administration. In: Auerbach A Feldstein M (eds) Handbook of Public Economics, vol. III. Elsevier, Amsterdam

Stigler G (1946) The economics of minimum wage Legislation. Am Econ Rev 36: 358-365

Tonin M (2011) Minimum wage and tax evasion: theory and evidence. J Public Econ 95(11-12): 1635-1651

Tonin M (2013) Too low to be true: the use of minimum thresholds to fight tax evasion. In: Fuest C Zodrow GR (eds) Critical Issues in Taxation and Development. MIT press, Boston

Williams CC (2007) Tackling undeclared work in Europe: lessons from a study of Ukraine. Eur J Ind Relat 13(2): 219-236 World Bank (2005) Enhancing job opportunities: eastern Europe and the former Soviet Union. World Bank, Washington World Bank (2006) Turkey. Country Economic Memorandum. World Bank, Washington

World Bank (2007) Informality: exit and exclusion. Washington

doi:10.1186/2193-9012-2-2

Cite this article as: Tonin: Underreporting of earnings and the minimum wage spike. IZA Journal of European Labor Studies 2013 2:2. 